\title{
BMJ Global Health Unsafe abortion and abortion-related death among 1.8 million women in India
}

\author{
Ryo Yokoe, ${ }^{1}$ Rachel Rowe, ${ }^{2}$ Saswati Sanyal Choudhury, ${ }^{3}$ Anjali Rani, ${ }^{4}$ \\ Farzana Zahir, ${ }^{5}$ Manisha Nair ${ }^{2}$
}

To cite: Yokoe R, Rowe $\mathrm{R}$, Choudhury SS, et al. Unsafe abortion and abortion-related death among 1.8 million women in India. BMJ Glob Health 2019;4:e001491. doi:10.1136/ bmjgh-2019-001491

Handling editor Seye Abimbola

- Additional material is published online only. To view please visit the journal online (http://dx.doi.org/10.1136/ bmjgh-2019-001491)

Received 10 February 2019 Revised 25 March 2019 Accepted 28 March 2019

Check for updates

(c) Author(s) (or their employer(s)) 2019. Re-use permitted under CC BY. Published by BMJ.

${ }^{1}$ Nuffield Department of Population Health, University of Oxford, Oxford, UK

${ }^{2}$ NPEU, Nuffield Department of Population Health, University of Oxford, Oxford, UK

${ }^{3}$ Department of Obstetrics and Gynaecology, Guwahati Medical College and Hospital, Guwahati, India

${ }^{4}$ Department of Obstetrics and Gynaecology, Institute of Medical Sciences, Banaras Hindu University, Varanasi, India ${ }^{5}$ Department of Obstetrics and Gynaecology, Assam Medical College, Dibrugarh, India

Correspondence to Dr Manisha Nair; manisha.nair@npeu.ox.ac.uk

\section{ABSTRACT}

Introduction Unsafe abortion is a preventable cause of maternal mortality. While studies report high number of abortions in India, the population-level rates of unsafe abortion and their risk factors are not well understood. Our objective was to analyse the rates of and risk factors for unsafe abortion and abortion-related maternal death in India.

Methods We conducted a secondary analysis of data from 1876462 pregnant women aged 15-58 years from nine states in the Indian Annual Health Survey (2010-2013). We calculated the rate of unsafe abortion and abortion-related mortality with $95 \% \mathrm{Cl}$. Multivariable logistic regression models examined the associations of sociodemographic characteristics, health seeking behaviours and family planning with unsafe abortion and abortion-related mortality.

Results There were 89447 abortions among 1876462 pregnant women in $2007-2011$ (4.8\%; $95 \% \mathrm{Cl} 4.8$ to 4.9$)$. Of these, 58266 were classified as unsafe $(67.1 \% ; 95 \% \mathrm{Cl} 66.7$ to 67.5$)$. There were 253 abortion-related maternal deaths $(0.3 \% ; 95 \% \mathrm{Cl} 0.2$ to 0.3$)$. Factors associated with unsafe abortion: maternal age 20-24 years (adjusted $\mathrm{OR}(\mathrm{aOR})$ : $1.13 ; 95 \% \mathrm{Cl} 1.09$ to 1.18 ), illiteracy (aOR: $1.48 ; 95 \% \mathrm{Cl} 1.39$ to 1.59 ), rural residence (aOR: $1.26 ; 95 \% \mathrm{Cl} 1.21$ to 1.32 ), Muslim religion (aOR: 1.16; $95 \% \mathrm{Cl} 1.12$ to 1.22), Schedule caste social group (aOR: $1.08 ; 95 \% \mathrm{Cl} 1.04$ to 1.12), poorest asset quintile (a0R: $1.45 ; 95 \% \mathrm{Cl} 1.38$ to 1.53 ), antenatal care (aOR: $0.69 ; 95 \% \mathrm{Cl} 0.67$ to 0.72 ), no surviving children (aOR: $1.30 ; 95 \% \mathrm{Cl} 1.16$ to 1.46 ), all surviving children being female (aOR: $1.12 ; 95 \% \mathrm{Cl} 1.07$ to 1.17 ), use of family planning methods (aOR: $0.69 ; 95 \% \mathrm{Cl} 0.66$ to 0.71 ). Factors associated with abortion-related deaths: maternal age 15-19 (aOR: $7.79 ; 95 \% \mathrm{Cl} 2.73$ to 22.23 ), rural residence (aOR: 3.28 ; $95 \% \mathrm{Cl} 1.76$ to 6.11 ), Schedule tribe social group (aOR: 4.06 ; $95 \% \mathrm{Cl} 1.39$ to 11.87 ).

Conclusion Despite abortion being legal, the high estimated prevalence of unsafe abortion demonstrates a major public health problem in India. Socioeconomic vulnerability and inadequate access to healthcare services combine to leave large numbers of women at risk of unsafe abortion and abortion-related death.

\section{INTRODUCTION}

Unsafe abortion is one of the preventable causes of maternal mortality ${ }^{1}$ yet, of the 55.7 million abortions that occurred globally each

\section{Key questions}

What is already known?

- There is a high prevalence of unsafe abortion in India, but population level rates and risk factors are not clearly understood.

What are the new findings?

- $67 \%$ of abortions in the study population in India were classified as unsafe, varying widely across the states (range $45.1 \%-78.3 \%$ ).

- There was a disproportionately higher risk of unsafe abortion among the vulnerable and disadvantaged populations in India.

- Young women aged 15-19 years were at the highest risk of dying from an abortion-related complication.

What do the new findings imply?

- Urgent work is needed to understand the barriers to safe abortion in India, despite the conducive legal environment.

year between 2010 and 2014, an estimated 25.1 million $(45.1 \%)$ were unsafe. ${ }^{2}$ Defined by the WHO as "the termination of an unintended pregnancy either by persons lacking the necessary skills or in an environment lacking the minimum medical standards or both," ${ }^{3}$ unsafe abortion is strongly associated with maternal complications such as haemorrhage, sepsis and trauma, and is the fourth leading cause of maternal death. ${ }^{4}$ Abortion plays a crucial role in the reproductive health of Indian women. ${ }^{5}$ An estimated 15.6 million abortions (14.1 million-17.3 million) were conducted in India in 2015. Women in India often turn to unqualified providers for abortion, ${ }^{6}$ despite abortion being made legal in the country through the Medical Termination of Pregnancy Act in the early 1970s. ${ }^{7}$ While several studies suggest a high prevalence of unsafe abortion and related complications among women of reproductive age group in India, ${ }^{2} 8{ }^{9}$ population-level rates of unsafe 
abortion and abortion-related mortality, and their risk factors are not well understood.

Previous research and theoretical arguments on abortion in India point to three main and interrelated factors that are important in understanding the context of seeking abortion: (1) women's labour force participation and educational attainment; (2) women's social class and ethnicity; (3) the predominant preference for male children. ${ }^{10}$ However, the combined effect of these factors has not been tested empirically. This is crucial to identify populations that are at a higher risk of seeking unsafe abortion in India to prevent maternal complications and deaths. The objectives of this study were to: (1) estimate the rates of unsafe abortion and abortion-related maternal mortality in nine states in India; (2) examine the sociodemographic characteristics of women who have an abortion compared with women who have a live birth; (3) investigate the risk factors for unsafe abortion; (4) investigate the risk factors for abortion-related maternal death in India.

\section{METHODS}

We conducted a secondary data analysis of the 2010-2013 round of India's Annual Health Survey (AHS) to analyse the rate of and risk factors for unsafe abortion and abortion-related maternal deaths in nine states in India.

\section{Definitions}

Based on the WHO definition, we used three criteria to identify 'unsafe abortions' using AHS data: (1) the setting where the abortion was performed (if induced) or completed (if spontaneous); (2) the person who performed or completed the abortion; (3) the gestational age at which the abortion was performed or completed. Abortions were classified as unsafe if they were not performed or completed in a health facility, not performed or completed by a skilled birth attendant, or performed or completed at 20 weeks of gestation ( $\sim 5$ months) or beyond. Abortions at or beyond 20 weeks' gestation were classified as unsafe because of the association with increased risk of maternal morbidity and mortality ${ }^{11}$ and because abortion beyond 20 weeks of pregnancy is illegal in India and under such a condition woman may be forced to seek abortion services from unqualified providers. The breakdown of unsafe abortion according to the three criteria is presented in online supplementary table S1.

We combined induced and spontaneous abortion into one category to minimise the risk of misclassification ${ }^{310}$ as most induced abortions are unreported or reported as spontaneous in surveys for legal, ethical and moral reasons. ${ }^{12}{ }^{13}$ Further, it was considered that determining safety of abortion was more important than examining types of abortion. Rees et al have argued that both induced and spontaneous abortion can result in unsafe abortion and present with complications. ${ }^{14}$

\section{Data source}

We used AHS (2010-2013) data. The AHS is a population-based household survey in which self-reported data on maternal and child health, demographics, birth and access to health and family planning services were collected from 4.3 million households in nine less developed states of India (Bihar, Chhattisgarh, Jharkhand, Madhya Pradesh, Odisha, Rajasthan, Uttar Pradesh, Uttarakhand and Assam), representing $50 \%$ of the country's population, $61 \%$ of births and $62 \%$ of maternal deaths. ${ }^{15} 16$ The AHS used a stratified simple random sampling (without replacement) to obtain a sample that was representative of and proportional to the size of the selected villages. Survey weights were developed to account for the sampling method. The survey administered four 'schedules' (or questionnaires): (1) Houselisting Schedule, (2) Household Schedule, (3) Women Schedule and (4) Mortality Schedule. Relevant data from all four schedules were merged for this study. Detailed objectives and associated methodology can be found in the AHS Report (Part I. 2014). ${ }^{16}$

\section{Study sample}

All women who provided information on their pregnancy (91.3\% most recent pregnancy and $8.7 \%$ on a previous pregnancy) were included. As in a previous study using the same dataset, women who had an abortion after 28 weeks were excluded as these were most likely to be stillbirths (according to the WHO definition for stillbirth).$^{15}$ A total of 1876462 women who reported being pregnant during the reference period 2007-2011 were included in the study. The mortality data were extracted from the mortality Schedule of the AHS and 253 abortion-related deaths were included, giving a total of 89447 abortions in 2007-2011. Among these, 253 women who died and 83 women who survived did not have information to examine the safety of abortion. Therefore, safety of abortion was examined in a total of 89111 women, of which 58266 had unsafe abortions and 30845 had safe abortions. online supplementary figure S1 further illustrates how we derived the samples for each study objective.

\section{Potential risk factors for unsafe abortion and abortion-related deaths}

We conducted a systematic search and review of the literature to identify risk factors for unsafe abortion and abortion-related death. Informed by the literature review, we developed conceptual frameworks to map the relationships of the risk factors with unsafe abortion (online supplementary file 1) and abortion-related mortality (online supplementary file 1) according to proximity to the outcome, and to guide selection of variables and analysis. Based on the literature review and conceptual frameworks, we grouped the population characteristics/ potential risk factors as sociodemographic characteristics, pregnancy-related characteristics, family characteristics, the use of family planning methods, and health seeking behaviours and mapped these against the available data 
in the AHS. We used survey data about household assets and principle component analysis ${ }^{17}$ to derive a measure of household wealth which is thought to be a good proxy of economic status. ${ }^{18}{ }^{19}$ We used data about the number of surviving children and the number of female children to derive the proportion of surviving female children. We considered the following as potential risk factors for unsafe abortion and/or abortion-related death: use of family planning method; place of residence; social group; religion; asset index/wealth; number of total surviving children; proportion of female children; maternal age; maternal education status; antenatal care (ANC) use; marital status; maternal employment; gestational month of abortion. The variables and their categorisation are described in online supplementary file 1 . All independent variables reflect characteristics of the household or women at the point of the survey. Baseline groups were chosen as the group with the least potential risk of having unsafe abortion, except for the use of family planning methods and the use of ANC (baseline-higher potential risk).

\section{Statistical analysis}

There were three outcomes of interest: (1) the outcome of the woman's pregnancy (live birth or abortion); (2) the safety of abortion (safe or unsafe); (3) the outcome of abortion (survived or died). The rate of abortion, unsafe abortion, and abortion-related death and the corresponding $95 \%$ CIs were calculated. The denominator for abortion rate was the total number of pregnancies in the reference period (2007-2011), and for the rates of unsafe abortion and abortion-related death was the total number of abortions during the same reference period. The characteristics of women who had an abortion were compared with those who had a live birth. We used univariable logistic regression analysis to examine the association between each independent variable and the outcomes (unsafe abortion and abortion-related mortality). Modelling a non-linear association between maternal age and the outcomes using fractional polynomials showed that maternal age acted in a non-linear fashion and was therefore used as a categorical variable.

Multivariable models were built using a stepwise forward regression approach, with our conceptual frameworks used to select the order for including the variables starting from distal to proximal (online supplementary figures S2 and S3). During model building for unsafe abortion we used a $p$ value $<0.05$ in the univariable analysis as a cut-off for including a variable. We used the Wald test at the 5\% significance level to determine if adding a variable significantly improved the model fit. In the multivariable model examining the risk factors for abortion-related death we chose to include all six potential risk factors, regardless of the results of the univariable analysis, because the number of variables available in the mortality dataset was small, and in order to control for confounding effects. Factors whose effects were attenuated by other variables in the multivariable regression were further examined to identify confounding. We calculated the proportion of factors reported to contribute to abortion-related maternal death.

Collinearity between independent variables was explored using pairwise correlation coefficients. We tested for interactions between variables for which there was a strong theoretical rationale. In the risk factor analysis for unsafe abortion, we therefore tested for interactions between employment and residence, employment and wealth, and social group and wealth. In the risk factor analysis for abortion-related mortality, interactions between social group and wealth, and social group and residence were examined. Potential interactions observed using univariable logistic regression were further assessed using the Wald test comparing the multivariable model with the relevant interaction terms with an empty model. No significant interactions were found at the $5 \%$ significance level.

We carried out an exploratory post hoc subgroup analysis to investigate the effect of the number of surviving female children in households where all children were female on the odds of unsafe abortion. All statistical analyses were carried out using Stata V.13.1 using the 'svy set' function to account for the stratified and clustered nature of the data. All proportions, means and CIs presented are therefore weighted for design effects and non-response. Two-sided $p$ values $<0.05$ were taken to indicate statistical significance.

Missing observations per variable were quantified, and we explored the 'type of missingness' by generating a new variable indicating missing data for each risk factor followed by logistic regression analysis to identify factors that predicted missingness. Based on this analysis, data were assumed to be 'missing at random' and three methods were used to address bias due to missing data: missing indicator method, complete case analysis and multiple imputation. ${ }^{20}$ The 'missing indicator' model in which missing data were grouped as a separate category was used as the final model. However, to maintain model stability, for variables that had $<1 \%$ missing data, a separate category for 'missing' was not generated.

\section{Study power}

For the fixed sample size of 89111 women who were classified as having a safe abortion and 58266 who had an unsafe abortion, this study had $90 \%$ power to detect an OR of $\geq 1.29$ or $\leq 0.75$ associated with unsafe abortion at $\mathrm{p}<0.05$ (two-tailed) for the risk factor with the lowest prevalence ('other religion' $0.6 \%$ ), and an OR of $\geq 1.43$ or $\leq 0.74$ for the risk factor with the highest prevalence ('being married' 99.6\%) in the study population.

For the fixed sample size of 89447 women who had an abortion and survived and 253 women who died during or within 42 days of the abortion procedure, this study had $80 \%$ power to detect an OR of $\geq 3.00$ associated with abortion-related death at $\mathrm{p}<0.05$ (two-tailed) for the risk factor with the lowest prevalence ('Christian religious group' $0.6 \%$ ), but not enough power to detect an OR less 
Table 1 Number and rate of abortion in nine states in India, using the AHS 2012-2013

\begin{tabular}{|c|c|c|c|}
\hline & $\begin{array}{l}\text { Women who reported a pregnancy, } \\
\text { who were alive at the time of the AHS, } \\
\text { and did not have an abortion after } 28 \\
\text { weeks' gestation, including those who } \\
\text { died after having an abortiont }\end{array}$ & $\begin{array}{l}\text { Women who had an abortion, } \\
\text { including those who died after } \\
\text { having an abortiont }\end{array}$ & Abortion rate* $(95 \% \mathrm{Cl})$ \\
\hline Overall & 1876715 & 89447 & 4.8 (4.8 to 4.9$)$ \\
\hline Assam & 165842 & 12306 & 6.5 (6.3 to 6.6$)$ \\
\hline Bihar & 348569 & 14562 & 4.3 (4.2 to 4.3$)$ \\
\hline Chhattisgarh & 105774 & 1658 & 1.6 (1.5 to 1.7$)$ \\
\hline Jharkhand & 149140 & 6212 & 4.1 (4.0 to 4.3$)$ \\
\hline Madhya Pradesh & 218817 & 7041 & 3.3 (3.2 to 3.4$)$ \\
\hline Odisha & 114053 & 6984 & 5.8 (5.7 to 6.0$)$ \\
\hline Rajasthan & 132680 & 4897 & 3.5 (3.3 to 3.6 ) \\
\hline Uttarakhand & 145923 & 6470 & 5.4 (5.2 to 5.5$)$ \\
\hline Uttar Pradesh & 495917 & 29317 & 5.9 (5.8 to 6.0$)$ \\
\hline
\end{tabular}

*The abortion rate is the number of abortions per 100 pregnancy outcomes (either an abortion or a live birth).

†Frequencies are unweighted (true counts). Rates/proportions are weighted for survey design and clustering effects.

AHS, Annual Health Survey.

than one at a clinically meaningful level. This study had $80 \%$ power to detect an OR of $\geq 1.43$ or $\leq 0.74$ for the risk factor with the highest prevalence (gestational month of abortion $<5$; 99.6\%) in the study population.

\section{Patient and public involvement}

This is not applicable since this was a secondary analysis of anonymous survey data.

\section{RESULTS \\ Rate of abortion, unsafe abortion and abortion-related mortality}

Among a total of 1876462 pregnant women in the study population, 89194 women had an abortion leading to an overall rate of $4.8 \%$ (95\% CI 4.8 to 4.9 ). The rate of abortion for each state is shown in table 1 . The prevalence of abortion was highest in Assam (6.5\%) and the lowest in Chhattisgarh (1.6\%). Out of 89111 women who survived and had sufficient information to examine the safety of abortion, 58266 women were classified as having an unsafe abortion. The overall rate of unsafe abortion was $67.1 \%$ (95\% CI 66.7 to 67.5 ) with five out of nine states above the overall rate (online supplementary table S3, figure 1). There was a large variation in the rate across the states: Assam had the lowest $(45.1 \%)$ and Chhattisgarh has the highest rate of unsafe abortion (78.3\%). Among a total of 89194 women who had an abortion, 253 were reported as abortion-related maternal death in the AHS, giving an abortion-related mortality rate of $0.3 \%$ (95\% CI 0.2 to 0.3 ) (online supplementary table S4).

The characteristics of women who had an abortion and those who had a live birth are presented in table 2 . Overall, despite statistically significant differences because of the large sample size, there were no clinically meaningful differences in age, education, residence, religion or social class background between the two groups. Two factors showed wide variation between the abortion and live birth groups. While $85.1 \%$ of women who had a live birth reported having some ANC, only $23.1 \%$ of women who had an abortion had ANC. This was true even after excluding women who had an early abortion $(<12$ weeks). Also, a marginally higher proportion of women who had an abortion belonged to the highest quintiles of the asset index.

\section{Risk factors for unsafe abortion in India}

The characteristics of the women who had an unsafe abortion and those who had a safe abortion are described in table 3. All sociodemographic characteristics (except marital status and maternal employment status) and all other characteristics (except self-reported mental illness) were found to be statistically significantly associated with unsafe abortion, and these associations were not substantially altered after adjustment for all potential risk factors (table 3).

Compared with women aged 25-29 years, the adjusted odds of unsafe abortion were $13 \%$ higher for younger women (20-24 years), and 18\% lower for older women (35-39 and 40-44 years). Women living in rural settings had 26\% higher odd of unsafe abortion compared with women living in urban settings. Muslim, Christian, or 'other' stated religion were associated with increased odds of unsafe abortion compared with Hindu. Education was inversely associated with unsafe abortion; women with no education were $48 \%$ more likely to have an unsafe abortion compared with women with university education or higher. Poorer women (in the lowest asset index quintile) had $45 \%$ higher odds of unsafe abortion, compared with women in the highest quintile. 


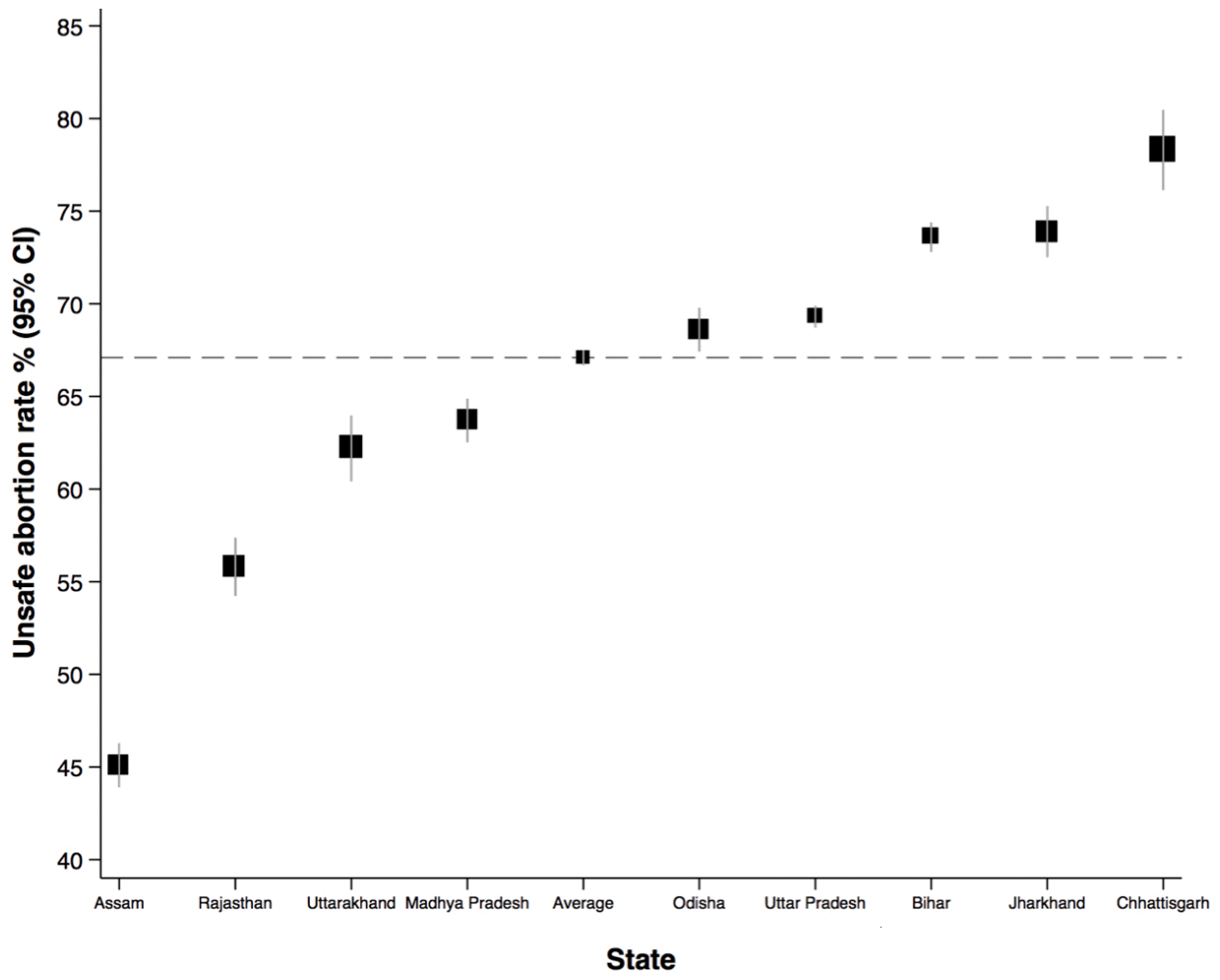

Figure 1 Rate of unsafe abortion in nine states in India.

In the univariable analysis, belonging to Schedule caste and Schedule tribe social groups was associated with a higher odds of unsafe abortion compared with the 'other' social groups. After adjusting for other risk factors the higher odds of unsafe abortion remained for the Schedule caste group, but for the Schedule tribe social group the association was reversed, with this group having $14 \%$ lower odds of unsafe abortion compared with the 'other' social group. Further analysis showed that the substantial change in the adjusted OR (aOR) was largely explained by the confounding effect of asset index (or wealth quintiles).

Women who had no children at the point of interview had a $30 \%$ higher odds of having unsafe abortion compared with women who had one to three children. Compared with women whose children were all boys, women with all female children had 12\% higher odds of having an unsafe abortion. This association was not significant if the woman had at least one surviving male child. On further examination through a subgroup analysis, we did not find any significant association between the number of surviving female children and unsafe abortion in households with all female children.

After adjusting for other risk factors, reported use of family planning methods at the point of survey was associated with a $21 \%$ lower odds of unsafe abortion. Women who had used ANC had $31 \%$ lower odds of unsafe abortion compared with those who did not use ANC. The results of complete case analysis and multiple imputations were not materially different from the 'missing indicator' model (online supplementary table S5).
Risk factors for abortion-related maternal deaths in India Of the six potential risk factors investigated (maternal age, place of residence, religion, social group, wealth/ asset index, gestational month), five were statistically significantly associated with abortion-related death (table 4). We found a non-linear (U-shaped) association between mother's age and abortion-related death (online supplementary figure S4). Compared with women aged 25-29 years, the aOR for abortion-related death was approximately eight times higher for women aged $<20$ years, and two times and four times higher for women aged $40-44$, and $\geq 45$ years, respectively. Women belonging to a Schedule tribe social group were four times as likely to die during or after having an abortion compared with the reference 'other' social group, but the association was not statistically significant for women belonging to a Schedule caste social group (OR: 1.38; $95 \%$ CI 0.52 to 3.66). Living in rural areas was associated with a higher odd of abortion-related death (aOR: 3.28; $95 \%$ CI 1.76 to 6.11 ). While the results of our missing indicator analysis were not materially different from the other models, one notable difference was that in the complete case model women who had an abortion at a gestational age of $\geq 5$ months had a significantly higher odds of dying compared with women who had an abortion before 5 months (aOR: 4.35; 95\% CI 2.53 to 7.50) (online supplementary table S6).

Further analysis of factors contributing to abortion-related maternal death showed that a third of the deaths were due to delays in receiving care at the health facility, $19 \%$ were due to inadequate care at health facility and 
Table 2 Characteristics of the study population by pregnancy outcome

\section{Women who had an}

abortion and survived* Women who had live births*

Characteristics

( $n=1787$ 268)

$P$ value†

\section{Maternal age (years)}

\begin{tabular}{|c|c|c|c|}
\hline $15-19$ & $3591(4.0)$ & $55882(3.0)$ & $<0.001$ \\
\hline $20-24$ & 25775 (28.9) & 591640 (32.2) & \\
\hline $25-29$ & 29310 (32.3) & 634182 (35.2) & \\
\hline $30-34$ & $17640(19.8)$ & 310726 (18.0) & \\
\hline $35-39$ & 8975 (10.2) & $132393(7.9)$ & \\
\hline $40-44$ & 2903 (3.5) & $44215(2.7)$ & \\
\hline$\geq 45$ & $1000(1.3)$ & $18214(1.1)$ & \\
\hline Missing & $0(0.0)$ & $16(0.0)$ & \\
\hline
\end{tabular}

\section{Marital status}

\begin{tabular}{|c|c|c|c|}
\hline Married & 88824 (99.6) & $1772493(99.2)$ & $<0.001$ \\
\hline Single & $370(0.4)$ & $14765(0.8)$ & \\
\hline Missing & $0(0)$ & $10(0)$ & \\
\hline \multicolumn{4}{|l|}{ Maternal education } \\
\hline Tertiary and above & $5221(5.8)$ & 85608 (4.5) & $<0.001$ \\
\hline Secondary school & $29703(29.5)$ & $495845(24.7)$ & \\
\hline Primary school/below & $22053(24.0)$ & $433415(23.4)$ & \\
\hline Illiterate & $32074(40.6)$ & 771004 (47.2) & \\
\hline Missing & $143(0.2)$ & $1396(0.1)$ & \\
\hline \multicolumn{4}{|l|}{ Maternal employment status } \\
\hline In-paid employment & $11130(11.0)$ & 269348 (13.9) & $<0.001$ \\
\hline Not in-paid employment & 77471 (89.0) & $1505539(85.5)$ & \\
\hline Missing & $593(0.6)$ & $12381(0.7)$ & \\
\hline \multicolumn{4}{|l|}{ Place of residence } \\
\hline Urban & $16601(21.4)$ & $257704(16.8)$ & $<0.001$ \\
\hline Rural & $72593(78.6)$ & $1529564(83.2)$ & \\
\hline Missing & $0(0)$ & $0(0)$ & \\
\hline \multicolumn{4}{|l|}{ Religion } \\
\hline Hindu & $73340(81.0)$ & $1468352(81.2)$ & $<0.001$ \\
\hline Muslim & $13541(17.3)$ & $267750(16.6)$ & \\
\hline Christian & $878(0.8)$ & $24558(1.2)$ & \\
\hline Others & $1293(0.8)$ & $25298(0.8)$ & \\
\hline Missing & $142(0.2)$ & $1310(0.1)$ & \\
\hline \multicolumn{4}{|l|}{ Social group } \\
\hline Others & $64591(73.2)$ & $1217533(68.8)$ & $<0.001$ \\
\hline Schedule caste & 16656 (19.9) & $345084(20.5)$ & \\
\hline Schedule tribe & $7805(6.7)$ & 223345 (10.6) & \\
\hline Missing & $142(0.2)$ & $1306(0.1)$ & \\
\hline \multicolumn{4}{|l|}{ Wealth/asset index } \\
\hline 5: Highest & $20678(23.3)$ & 329699 (18.7) & $<0.001$ \\
\hline 4 & $18242(20.4)$ & 332053 (18.7) & \\
\hline 3 & $16452(19.1)$ & 328566 (19.1) & \\
\hline 2 & $14646(15.9)$ & 339755 (18.2) & \\
\hline
\end{tabular}

Continued 
Table 2 Continued

\begin{tabular}{|c|c|c|c|}
\hline Characteristics & $\begin{array}{l}\text { Women who had an } \\
\text { abortion and survived* } \\
(\mathrm{n}=89 \text { 194) }\end{array}$ & $\begin{array}{l}\text { Women who had live births* } \\
\text { (n=1 } 787 \text { 268) }\end{array}$ & $P$ value \\
\hline 1: Lowest & $12799(14.1)$ & $339366(18.7)$ & \\
\hline Missing & $6377(7.1)$ & $117829(6.6)$ & \\
\hline \multicolumn{4}{|l|}{ Antenatal care use } \\
\hline No & $69113(76.9)$ & $244447(14.9)$ & $<0.001$ \\
\hline Yes & $20081(23.1)$ & $1542821(85.1)$ & \\
\hline Missing & $0(0)$ & $0(0)$ & \\
\hline \multicolumn{4}{|c|}{ Self-reported mental illness } \\
\hline No & $88,42(99.1)$ & 1773403 (99.2) & $<0.001$ \\
\hline Yes & $627(0.8)$ & $12505(0.7)$ & \\
\hline Missing & $143(0.2)$ & $1360(0.1)$ & \\
\hline \multicolumn{4}{|c|}{ Number of surviving children at the point of interview } \\
\hline 0 & $2910(3.3)$ & $21854(1.3)$ & $<0.001$ \\
\hline $1-3$ & $55971(60.2)$ & $1366546(74.5)$ & \\
\hline 4 or more & $13,92(17.6)$ & $394976(23.9)$ & \\
\hline Missing & $16388(19.0)$ & $3892(0.3)$ & \\
\hline \multicolumn{4}{|c|}{$\begin{array}{l}\text { Proportion of surviving female children among total } \\
\text { surviving children }\end{array}$} \\
\hline $0 \%$ & 19825 (21.3) & $464452(25.2)$ & $<0.001$ \\
\hline $10 \%-30 \%$ & $9710(11.9)$ & $250552(15.0)$ & \\
\hline $40 \%-60 \%$ & $18198(20.6)$ & $452104(25.8)$ & \\
\hline $70 \%-90 \%$ & $7495(8.6)$ & $230421(13.1)$ & \\
\hline $100 \%$ & $15737(16.7)$ & $377224(20.0)$ & \\
\hline Missing & $18229(21.0)$ & $12515(0.9)$ & \\
\hline \multicolumn{4}{|c|}{ Family planning (at the point of interview) } \\
\hline No & 35117 (39.7) & $690246(38.7)$ & $<0.001$ \\
\hline Yes & 38960 (42.5) & 832645 (46.1) & \\
\hline Missing & $15117(17.8)$ & 264377 (15.2) & \\
\hline
\end{tabular}

${ }^{*}$ Frequencies are unweighted (true counts). Rates/proportions are weighted for survey design and clustering effects. †P value shows two-sided $\mathrm{p}$ value for $\chi^{2}$ test for difference in proportions.

$17 \%$ were due to a failure to recognise the seriousness of the condition (online supplementary table S7).

\section{DISCUSSION}

\section{Main findings}

To our knowledge, this study is the first large population-based study to examine unsafe abortion and abortion-related morality in India. The overall rate of abortion was estimated to be $4.8 \%$, ranging from $1.6 \%$ to $6.5 \%$ among the nine states. Overall, $67.1 \%$ of abortions were classified to be unsafe, varying widely across the states with the highest being $78.3 \%$ and the lowest being $45.1 \%$. The overall rate of abortion-related death was estimated to be $0.3 \%$ and did not vary appreciably across the states.

There were no clinically meaningful differences between women who had an abortion and those who had a live birth, but a significantly lower proportion of the women who had an abortion had ANC, and a higher proportion were educated and belonged to higher socioeconomic status. We found a strong association of unsafe abortion with sociodemographic factors (younger maternal age, lower socioeconomic status, Muslim religion, rural residence, illiteracy, schedule caste social group), healthcare service utilisation (ANC), family characteristics (number of surviving children and proportion of surviving female children) and family planning use. We found that factors associated with unsafe abortions were different from those associated with abortion-related mortality. Teenage women (aged 15-19 years) were found to have the highest risk of abortion-related death in addition to rural residence and lower socioeconomic status. 
Table 3 Unadjusted and adjusted associations between sociodemographic and family characteristics, health seeking behaviour, family planning and unsafe abortion

\begin{tabular}{|c|c|c|c|c|}
\hline $\begin{array}{l}\text { Women who had } \\
\text { unsafe abortion* } \\
(n=58 \text { 266) }\end{array}$ & $\begin{array}{l}\text { Women who had } \\
\text { safe abortion* } \\
\text { ( } n=30 \text { 845) }\end{array}$ & $\begin{array}{l}\text { Unadjusted OR }(95 \% \mathrm{Cl}) \dagger \\
\text { missing indicator } \\
(\mathrm{n}=89 \text { 111) }\end{array}$ & $P$ value & $\begin{array}{l}\text { Adjusted OR }(95 \% \mathrm{Cl}) \dagger \\
\text { missing indicator } \\
(\mathrm{n}=89 \text { 111) }\end{array}$ \\
\hline
\end{tabular}

Sociodemographic characteristics

Maternal age (years)

\begin{tabular}{|c|c|c|c|c|c|c|}
\hline $15-19$ & $2548(4.2)$ & $1041(3.4)$ & 1.22 (1.11 to 1.33$)$ & $<0.001$ & 1.09 (1.00 to 1.18$)$ & $<0.001$ \\
\hline $20-24$ & $17852(30.3)$ & 7889 (24.6) & $1.17(1.12$ to 1.23$)$ & & 1.13 (1.09 to 1.18$)$ & \\
\hline $25-29$ & 18932 (32.3) & $10354(32.4)$ & 1.00 (ref) & & 1.00 (ref) & \\
\hline 35-39 & $5508(9.7)$ & 3460 (12.0) & 0.87 (0.82 to 0.92$)$ & & 0.82 (0.78 to 0.87$)$ & \\
\hline $40-44$ & $1833(3.4)$ & $1070(3.9)$ & 0.94 (0.85 to 1.04$)$ & & $0.82(0.75$ to 0.89$)$ & \\
\hline$\geq 45$ & $685(1.3)$ & 315 (1.3) & 1.00 (0.86 to 1.18$)$ & & 0.95 (0.83 to 1.09$)$ & \\
\hline \multicolumn{7}{|l|}{ Marital status } \\
\hline Married & $58.012(99.6)$ & 30729 (99.6) & 0.91 (0.69 to 1.20$)$ & 0.5125 & N/Aף & \\
\hline Single & $254(0.4)$ & $116(0.4)$ & 1.00 (ref) & & N/Aף & \\
\hline Missing & $0(0)$ & $0(0)$ & $\mathrm{N} / \mathrm{A}$ & & N/Aף & \\
\hline \multicolumn{7}{|l|}{ Maternal education } \\
\hline Illiterate & 23165 (43.9) & 8879 (32.6) & 2.07 (1.92 to 2.23 ) & & 1.48 (1.39 to 1.59$)$ & \\
\hline Missing & $95(0.2)$ & $48(0.1)$ & $1.92(1.21$ to 3.05$)$ & & $N / A^{\star \star}$ & \\
\hline \multicolumn{7}{|l|}{$\begin{array}{l}\text { Maternal } \\
\text { employment status }\end{array}$} \\
\hline $\begin{array}{l}\text { In-paid } \\
\text { employment }\end{array}$ & $740(11.0)$ & 3716 (10.6) & 1.00 (ref) & 0.0606 & N/A & \\
\hline $\begin{array}{l}\text { Not in-paid } \\
\text { employment }\end{array}$ & 50474 (88.3) & 26927 (88.8) & 0.96 (0.91 to 1.01$)$ & & N/Aף & \\
\hline Missing & $391(0.7)$ & $202(0.6)$ & & & N/A I & \\
\hline Muslim & 9209 (17.8) & 4319 (16.2) & 1.13 (1.08 to 1.18$)$ & & 1.16 (1.12 to 1.22$)$ & \\
\hline Christian & $625(0.9)$ & $253(0.7)$ & 1.33 (1.11 to 1.60$)$ & & 1.39 (1.20 to 1.62$)$ & \\
\hline Others & $1016(0.9)$ & $277(0.6)$ & 1.48 (1.23 to 1.76$)$ & & 2.05 (1.78 to 2.36$)$ & \\
\hline Missing & $94(0.2)$ & $48(0.1)$ & 1.23 (0.78 to 1.95$)$ & & N/A†† & \\
\hline \multicolumn{7}{|l|}{ Social group } \\
\hline Others & 41708 (72.4) & 22826 (74.8) & 1.00 (ref) & $<0.001$ & 1.00 (ref) & $<0.001$ \\
\hline Schedule caste & 11351 (20.5) & 5290 (18.9) & 1.12 (1.07 to 1.17$)$ & & 1.08 (1.04 to 1.12$)$ & \\
\hline Schedule tribe & $5113(7.0)$ & $2681(6.2)$ & 1.17 (1.10 to 1.25$)$ & & 0.86 (0.81 to 0.90$)$ & \\
\hline Missing & $94(0.2)$ & $48(0.1)$ & $1.24(0.78$ to 1.97$)$ & & $N / A^{\star *}$ & \\
\hline \multicolumn{7}{|l|}{ Wealth/asset index } \\
\hline 5: Highest & 11977 (20.6) & $8684(30,2)$ & 1.00 (ref) & $<0.001$ & 1.00 (ref) & $<0.001$ \\
\hline 4 & $11496(19.8)$ & $6726(21.8)$ & 1.29 (1.23 to 1.36$)$ & & 1.08 (1.03 to 1.13$)$ & \\
\hline 3 & 11012 (19.8) & $5421(17.5)$ & 1.57 (1.49 to 1.66$)$ & & 1.18 (1.13 to 1.24$)$ & \\
\hline 2 & $10113(16.8)$ & $4521(13.7)$ & 1.67 (1.58 to 1.76$)$ & & $1.24(1.18$ to 1.31$)$ & \\
\hline
\end{tabular}

Continued 
Table 3 Continued

\begin{tabular}{|c|c|c|c|c|c|c|}
\hline & $\begin{array}{l}\text { Women who had } \\
\text { unsafe abortion* } \\
(n=58266)\end{array}$ & $\begin{array}{l}\text { Women who had } \\
\text { safe abortion* } \\
\text { ( } n=30 \text { 845) }\end{array}$ & $\begin{array}{l}\text { Unadjusted OR }(95 \% \mathrm{Cl}) \dagger \\
\text { missing indicator } \\
(\mathrm{n}=89 \text { 111) }\end{array}$ & $P$ value & $\begin{array}{l}\text { Adjusted OR }(95 \% \mathrm{Cl}) \dagger \\
\text { missing indicator } \\
(\mathrm{n}=89 \text { 111) }\end{array}$ & $\mathbf{P}$ value§ \\
\hline 1: Lowest & $9443(15.7)$ & 3348 (9.8) & 2.02 (1.90 to 2.14$)$ & & 1.45 (1.38 to 1.53$)$ & \\
\hline Missing & $4225(7.2)$ & $2145(7.1)$ & 1.46 (1.36 to 1.57$)$ & & 1.33 (1.25 to 1.42$)$ & \\
\hline \multicolumn{7}{|c|}{$\begin{array}{l}\text { Health seeking } \\
\text { behaviour }\end{array}$} \\
\hline \multicolumn{7}{|c|}{ Antenatal care use } \\
\hline No & $46392(79.7)$ & 22656 (71.2) & 1.00 (ref) & $<0.001$ & 1.00 (ref) & $<0.001$ \\
\hline Yes & $11874(20.3)$ & $8189(28.8)$ & 0.63 (0.60 to 0.66$)$ & & 0.69 (0.67 to 0.72$)$ & \\
\hline Missing & (0) & (0) & N/A & & N/A & \\
\hline \multicolumn{7}{|c|}{$\begin{array}{l}\text { Family } \\
\text { characteristics }\end{array}$} \\
\hline \multicolumn{7}{|c|}{$\begin{array}{l}\text { Number of surviving } \\
\text { children at the point } \\
\text { of interview }\end{array}$} \\
\hline 0 & 2203 (3.9) & 703 (1.9) & 1.85 (1.66 to 2.07 ) & $<0.001$ & 1.30 (1.16 to 1.46$)$ & $<0.001$ \\
\hline $1-3$ & 35751 (59.8) & 20165 (61.5) & 1.00 (ref) & & 1.00 (ref) & \\
\hline 4 or more & 8991 (17.2) & $4924(19.8)$ & 0.94 (0.90 to 0.99$)$ & & 0.96 (0.91 to 1.00$)$ & \\
\hline Missing & 11321 (19.2) & $5053(16.8)$ & $1.06(1.01$ to 1.11$)$ & & 0.79 (0.68 to 0.93$)$ & \\
\hline \multicolumn{7}{|c|}{$\begin{array}{l}\text { Proportion of } \\
\text { surviving female } \\
\text { children among total } \\
\text { surviving children }\end{array}$} \\
\hline $0 \%$ & 12596 (21.0) & $7206(21.8)$ & 1.00 (ref) & $<0.001$ & 1.00 (ref) & $<0.001$ \\
\hline $10 \%-30 \%$ & $6148(11.6)$ & 3554 (12.4) & 0.97 (0.91 to 1.03$)$ & & 0.97 (0.92 to 1.03$)$ & \\
\hline $40 \%-60 \%$ & $11704(20.4)$ & $6481(21.2)$ & 0.99 (0.94 to 1.05$)$ & & 1.05 (1.00 to 1.10$)$ & \\
\hline $70 \%-90 \%$ & $4736(8.3)$ & $2749(9.0)$ & 0.96 (0.90 to 1.03$)$ & & 1.00 (0.94 to 1.06$)$ & \\
\hline $100 \%$ & $10343(17.0)$ & $5379(16.1)$ & $1.10(1.04$ to 1.15$)$ & & $1.12(1.07$ to 1.17$)$ & \\
\hline Missing & 12739 (21.6) & 5476 (19.6) & 1.14 (1.08 to 1.20$)$ & & 1.43 (1.23 to 1.66$)$ & \\
\hline \multicolumn{7}{|c|}{ Family planning } \\
\hline \multicolumn{7}{|c|}{$\begin{array}{l}\text { Use of family } \\
\text { planning methods at } \\
\text { the point of interview }\end{array}$} \\
\hline No & $24762(42.2)$ & 10325 (34.7) & 1.00 (ref) & $<0.001$ & 1.00 (ref) & $<0.001$ \\
\hline Yes & 22823 (39.1) & $16101(49.4)$ & 0.65 (0.63 to 0.67$)$ & & 0.69 (0.66 to 0.71$)$ & \\
\hline Missing & $10681(18.8)$ & 4419 (15.9) & 0.97 (0.92 to 1.02$)$ & & 1.02 (0.97 to 1.06$)$ & \\
\hline \multicolumn{7}{|l|}{ Others } \\
\hline \multicolumn{7}{|c|}{$\begin{array}{l}\text { Self-reported mental } \\
\text { illness }\end{array}$} \\
\hline No & $57752(99.0)$ & 30589 (99.1) & 1.0 (ref) & 0.5773 & N/Aף & \\
\hline Yes & $420(0.8)$ & $207(0.7)$ & 1.07 (0.88 to 1.31$)$ & & N/Aף & \\
\hline Missing & $94(0.2)$ & $49(0.1)$ & $1.20(0.76$ to 1.90$)$ & & N/A & \\
\hline
\end{tabular}

${ }^{*}$ Frequencies are unweighted (true counts). Rates/proportions are weighted for survey design and clustering effects.

†The $95 \%$ Cls were calculated using linearised standard errors $p$ value for a t-test showing the significance level for the overall univariable regression model. † Multivariable logistic regression, adjusting for the other variables/potential risk factors in the final model.

$\S \mathrm{P}$ value for a Wald test indicating whether the incremental adjustment for an independent variable significantly improves the fit of the model.

IN/As are shown because these variables were not included in the final multivariable logistic model.

${ }^{*} \mathrm{~N} /$ As are shown because the OR associated with the missing category was extremely large, which can be explained by the small number of missing values in each group.

$\dagger+\mathrm{N} / \mathrm{A}$ is shown because the OR was omitted due to collinearity between missing categories.

$\ddagger \ddagger P$ value for a t-test showing the significance level for the overall univariable regression model.

\section{Strengths and limitations}

Use of data from the AHS, the largest health survey in India, allowed us to conduct an adequately powered, robust investigation of a wide range of potential risk factors. Our findings are reasonably generalisable for high burden states, but may not be generalisable to the rest of India. To our knowledge, this study is the first in India to identify risk factors associated with unsafe 
Table 4 Unadjusted and adjusted associations between sociodemographic characteristics, gestational age at abortion and abortion-related maternal death

\begin{tabular}{|c|c|c|c|c|c|c|}
\hline & $\begin{array}{l}\text { Women } \\
\text { who died of } \\
\text { abortion* } \\
(n=253)\end{array}$ & $\begin{array}{l}\text { Women who } \\
\text { survived } \\
\text { abortion* } \\
(\mathrm{n}=89 \text { 194) }\end{array}$ & $\begin{array}{l}\text { Unadjusted OR }(95 \% \\
\text { Cl)† } \\
\text { Missing indicator } \\
(\mathrm{n}=89 \text { 443) }\end{array}$ & $P$ value & $\begin{array}{l}\text { Adjusted OR } ¥(95 \% \\
\text { Cl) } \dagger \\
\text { Missing indicator } \\
\text { (n=89 443) }\end{array}$ & $\begin{array}{l}\mathbf{P} \\
\text { value§}\end{array}$ \\
\hline \multicolumn{7}{|c|}{ Maternal age (years) } \\
\hline $15-19$ & $36(13.5)$ & $3591(4.0)$ & 6.53 (1.71 to 24.95$)$ & $<0.001$ & 7.79 (2.73 to 22.23 ) & $<0.001$ \\
\hline $20-24$ & 59 (23.6) & 25775 (28.9) & 3.13 (1.06 to 9.22$)$ & & 4.29 (2.00 to 9.20$)$ & \\
\hline $25-29$ & $54(19.9)$ & $29310(32.3)$ & 1.00 (ref) & & 1.00 (ref) & \\
\hline $30-34$ & $42(17.0)$ & $17640(19.8)$ & 0.8 (0.31 to 2.04$)$ & & 1.12 (0.63 to 1.96$)$ & \\
\hline $35-39$ & $38(15.6)$ & 8975 (10.2) & 4.1 (1.18 to 14.28$)$ & & 5.95 (2.11 to 16.81$)$ & \\
\hline $40-44$ & $16(5.7)$ & $2903(3.5)$ & 1.51 (0.55 to 4.16$)$ & & 2.07 (1.06 to 4.07 ) & \\
\hline$\geq 45$ & $8(4.8)$ & $1000(1.3)$ & 3.52 (1.1 to 11.22$)$ & & 4.35 (1.77 to 10.67$)$ & \\
\hline Missing & $0(0.0)$ & $0(0)$ & N/A & & N/A & \\
\hline \multicolumn{7}{|l|}{ Place of residence } \\
\hline Urban & $24(13.0)$ & $16601(21.4)$ & 1.00 (ref) & $<0.001$ & 1.00 (ref) & $<0.001$ \\
\hline Rural & $225(86.2)$ & 72593 (78.6) & 4.56 (2.46 to 8.47$)$ & & 3.28 (1.76 to 6.11$)$ & \\
\hline Missing & $4(0.4)$ & $0(0)$ & N/A & & N/A & \\
\hline \multicolumn{7}{|l|}{ Religion } \\
\hline Hindu & $202(81.5)$ & $73340(81.0)$ & 1.00 (ref) & 0.4193 & 1.00 (ref) & 0.1618 \\
\hline Others & $48(18.9)$ & $15712(22.2)$ & 0.82 (0.33 to 2.02 ) & & 0.94 (0.35 to 2.55$)$ & \\
\hline Missing & $3(0.8)$ & $142(0.2)$ & N/A & & N/Aף & \\
\hline \multicolumn{7}{|l|}{ Social group } \\
\hline Others & $167(68.5)$ & 64591 (73.2) & 1.00 (ref) & 0.0138 & 1.00 (ref) & 0.0035 \\
\hline Schedule caste & $48(18.5)$ & $16656(19.9)$ & 1.38 (0.52 to 3.66$)$ & & 1.25 (0.43 to 3.60$)$ & \\
\hline Schedule tribe & 35 (11.8) & $7805(6.8)$ & 4.77 (1.74 to 13.05$)$ & & 4.06 (1.39 to 11.87$)$ & \\
\hline Missing & $3(1.1)$ & $143(0.2)$ & N/A & & N/Aף & \\
\hline \multicolumn{7}{|l|}{ Wealth/asset index } \\
\hline 5: Highest & $45(22.4)$ & $20678(23.3)$ & 1.00 (ref) & $<0.001$ & 1.00 (ref) & $<0.001$ \\
\hline 4 & 47 (16.9) & $18242(20.4)$ & 0.86 (0.53 to 1.40$)$ & & 0.65 (0.39 to 1.10$)$ & \\
\hline 3 & $52(18.8)$ & $16452(19.1)$ & 5.81 (2.76 to 12.22$)$ & & 3.81 (1.86 to 7.83 ) & \\
\hline 2 & $54(18.7)$ & $14646(15.9)$ & 2.18 (0.85 to 5.61$)$ & & 1.33 (0.50 to 3.57$)$ & \\
\hline 1: Lowest & $44(18.7)$ & $12799(14.1)$ & 3.56 (1.42 to 8.92$)$ & & 2.08 (0.73 to 5.94$)$ & \\
\hline Missing & $11(4.5)$ & $6377(7.1)$ & N/A & & 0.33 (0.16 to 0.70$)$ & \\
\hline \multicolumn{7}{|l|}{ Gestational month } \\
\hline$<5$ months & $205(77.8)$ & $86792(97.2)$ & 1.00 (ref) & $<0.001$ & 1.00 (ref) & $<0.001$ \\
\hline$\geq 5$ months & $21(10.1)$ & $2337(2.7)$ & 1.87 (0.97 to 3.61$)$ & & $1.58(0.80$ to 3.13$)$ & \\
\hline Missing & $27(6.0)$ & $65(0.1)$ & N/A & & N/Aף & \\
\hline
\end{tabular}

${ }^{*}$ Frequencies are unweighted (true counts). Rates/proportions are weighted for survey design and clustering effects.

†The $95 \%$ Cls were calculated using linearised standard errors.

$\ddagger$ Multivariable logistic regression, adjusting for the other variables/potential risk factors in the final model.

$\S \mathrm{P}$ value for a Wald test indicating whether the incremental adjustment for an independent variable significantly improves the fit of the model.

IN/As are shown because the OR associated with the missing category was extremely large, which can be explained by the small number of missing values in each group.

${ }^{\star *} P$ value for a t-test showing the significance level for the overall univariable regression model. 
abortion and abortion-related death at a population level.

The rate of unsafe abortion and abortion-related mortality may be underestimated due to underreporting of abortion and misclassification of abortion-related death. Women are often reluctant to report induced abortion regardless of the legal context of abortion. ${ }^{12}{ }^{13}$ Similarly, women might have provided inaccurate information on the three criteria used to classify the safety of abortion. Since the cause of maternal mortality was reported by family members without validation, deaths occurring after having an abortion might have been misclassified as death caused by haemorrhage or pregnancy-related deaths. In an effort to minimise the possibility of misclassification between abortion and stillbirth, women who reported having an abortion after 28 weeks were excluded.

As the survey design was cross-sectional, causality cannot be inferred from the study results. We did not have data on the method of abortion, therefore this could not be used as a criterion for classifying the safety of abortion. However, methods used to estimate unsafe abortion rates vary widely across studies, ${ }^{21-24}$ and there are discrepancies between how the WHO definition is worded and how it has been practically applied to measure the burden of unsafe abortion. ${ }^{25}$ Because there were some factors identified in the literature as important risk factors for unsafe abortion (including, eg, sexual behaviour, partners' approval of abortion, reasons for abortion, pregnancy wantedness and exposure to media), for which data from the AHS were not available, there is a risk of residual confounding. Finally, because death is a rare outcome, this study had restricted statistical power to detect significant associations between risk factors and abortion-related death.

\section{Other evidence and implications}

Our estimates of the prevalence of unsafe abortion in these nine Indian states fit with regional estimates from a study in south-central Asia (57.8\%; $95 \%$ CI 50.3 to 65.9$),{ }^{2}$ but are much higher than in a study conducted in India using data from the 2015 Health Facilities Survey and national abortion medication sales, which concluded that among 15.6 million abortions occurring in 2015, 0.8 million (5\%) abortions were unsafe. ${ }^{8}$ This discrepancy is possibly because in this latter study unsafe abortion was defined only as a surgical abortion performed outside of a health facility, without considering who performed the abortion or when the abortion was performed.

Our results suggest a pervading theme of vulnerability for unsafe abortion related to low socioeconomic status and teenage pregnancy. While there was an increased prevalence of abortion among educated women, the risks of unsafe abortion, and of death related to abortion, were higher among uneducated women, consistent with previous literature. ${ }^{22}{ }^{26}$ Although the prevalence of abortion was higher among women with higher socioeconomic status, women from lower socioeconomic status, and 'Schedule caste' social group, were more likely to have an unsafe abortion, and to die from abortion-related causes. This is consistent with evidence showing that disadvantaged minority groups in Brazil are at a higher risk of unsafe abortion. ${ }^{22}$ Our finding that women belonging to 'Schedule tribe' groups were less likely to have an unsafe abortion might be explained by different health seeking behaviours in women from these groups or may have arisen due to residual confounding. Nevertheless, the risk of abortion-related death was higher in both social groups, indicating the possibility of disparities in access to adequate healthcare for management of abortion complications.

The importance of access to adequate healthcare is also highlighted by our findings on place of residence. Compared with women in urban settings, women living in rural settings were more likely to have an unsafe abortion and more likely to die from an abortion-related cause. More than half $(56.28 \%)$ of the abortion-related deaths in this study were due to a lack of access to appropriate healthcare (ie, delay in receiving healthcare at facility, inadequate care at health facility and lack of transport to the facility). About $70 \%$ of India's population live in rural settings, but safe abortion services are rarely available at rural facilities. ${ }^{21}$ In the state of Rajasthan, for example, rural settings had an estimated 0.85 certified abortion facilities per 100000 population, compared with 3.65 in urban settings. ${ }^{27}$

Lack of access to appropriate health services is also reflected in our results in other ways. Our complete case analysis showed that gestational age at the time of the abortion was found to be one of the strongest risk factors for abortion-related mortality, which is consistent with the finding of one study conducted in the USA. ${ }^{11}$ Although it was not possible to examine the safety of abortion among women who died, this variable serves as a proxy for unsafe abortion, supporting the evidence that an abortion-related death is most likely to occur after an unsafe abortion. ${ }^{14}$ The process of seeking an abortion, or care for complications of spontaneous or induced abortion, can involve multiple visits to different providers, resulting in delays, with potentially devastating consequences. ${ }^{28-30}$ In India, preventing unwanted pregnancies through family planning is a key strategy for reducing abortion rates. ${ }^{31} 32$ Access to family planning services, may also be important for reducing the risks of having an unsafe abortion. ${ }^{233344}$ Finally, our results also suggest that antenatal check-ups may be important in reducing the risk of maternal morbidity and mortality resulting from complications, even if they plan to seek an abortion.

Beside socioeconomic factors, women's age was significantly associated with unsafe abortion and abortion-related death. Younger women ( $\leq 24$ years) were at a higher risk of unsafe abortion and risk of abortion-related death was highest among teenage women (15-19 years). Older women ( $\geq 30$ years) were less likely to have an unsafe abortion, but were more likely to die as a result of an abortion. Other studies, in Bangladesh ${ }^{26}$ and Nigeria, ${ }^{35}$ found similar results in relation to maternal age and unsafe abortion. Although female selective abortion (FSA) is illegal in India, the practice is still prevalent. ${ }^{36-38}$ 
Our finding that women with no male children were more likely to have an unsafe abortion compared with women who had at least one male child is consistent with FSA being sought from unregistered and unqualified abortion providers. ${ }^{3} 39$

\section{CONCLUSION}

The high estimated prevalence of unsafe abortion in India demonstrates a critical public health problem. Consistent with research in other low-and-middle income countries (LMICs), our results demonstrate that socioeconomic vulnerability, teenage pregnancy and inadequate access to healthcare services combine to leave large numbers of women at risk of unsafe abortion and abortion-related death. There is an urgent need to ensure adequate access to family planning, early abortion services and adequate care for management of postabortion complications, particularly in disadvantaged areas. Further research providing empirical evidence on the barriers to safe abortion services in India is essential to reduce unsafe abortions and deaths, particularly in populations identified to be at a higher risk.

Acknowledgements We thank Noon Altijani, DPhil student at the Nuffield Department of Population Health (NDPH) and Charles Opondo, Researcher in Statistics and Epidemiology, National Perinatal Epidemiology Unit, NDPH, for their help with survey commands and multiple imputation analysis, respectively. The AHS was conducted by the Office of the Registrar General \& Census Commissioner, India (http://censusindia.gov.in/vital statistics/AHSBulletins/ahs.html). We obtained the data from the Indian Government's Data Sharing Portal where the anonymised data is freely available for research and other purposes.

Contributors RY reviewed the literature, conducted the analysis and wrote the first draft of the manuscript. MN led the conceptualisation of the project, compiled the data, supervised the data analysis, interpretation and discussion of the results, and edited the paper. RR supervised the data analysis, interpretation and discussion of the results, and edited the paper. SSC, FZ and AR contributed to interpreting the data, and editing the paper.

Funding The study was funded by a Medical Research Council Career Development Award to Manisha Nair (Grant Ref: MR/P022030/1). The funder had no role in the study design, data analysis, data interpretation, or writing of the report. MN had full access to all the data in the study and had final responsibility for the decision to submit for publication.

Competing interests None declared.

Patient consent for publication Not required.

Ethics approval The anonymised data are freely available through the Indian Government's Data Sharing Portal.

Provenance and peer review Not commissioned; externally peer reviewed.

Data sharing statement Data are available in a public, open access repository.

Open access This is an open access article distributed in accordance with the Creative Commons Attribution 4.0 Unported (CC BY 4.0) license, which permits others to copy, redistribute, remix, transform and build upon this work for any purpose, provided the original work is properly cited, a link to the licence is given, and indication of whether changes were made. See: https://creativecommons.org/ licenses/by/4.0/.

\section{REFERENCES}

1. Grimes DA, Benson J, Singh S, et al. Unsafe abortion: the preventable pandemic. The Lancet 2006;368:1908-19.

2. Ganatra B, Gerdts C, Rossier C, et al. Global, regional, and subregional classification of abortions by safety, 2010-14: estimates from a Bayesian hierarchical model. The Lancet 2017;390:2372-81.
3. WHO. Unsafe abortion: global and regional estimates of the incidence of unsafe abortion and associated mortality in 2008 Geneva. Available: http://www.who.int/reproductivehealth/ publications/unsafe_abortion/9789241501118/en/[Accessed 5 Feb 2019].

4. Khan KS, Wojdyla D, Say L, et al. Who analysis of causes of maternal death: a systematic review. The Lancet 2006;367:1066-74.

5. POPLINE by K4Health. Abortion in India: what does the National family health survey tell us?. Available: https://www.popline.org/ node/280482 [Accessed 5 Feb 2019].

6. Haddad LB, Nour NM. Unsafe abortion: unnecessary maternal mortality. Rev Obstet Gynecol 2009;2:122-6.

7. POPLINE K4Health. Realizing reproductive choice and rights: Abortion and contraception in India. Available: https://www.popline. org/node/562996 [Accessed 5 Feb 2019].

8. Singh S, Shekhar C, Acharya R, et al. The incidence of abortion and unintended pregnancy in India, 2015. The Lancet Global Health 2018;6:e111-20.

9. Duggal R, Ramachandran V. The abortion assessment ProjectIndia: key findings and recommendations. Reproductive Health Matters 2004;12:122-9.

10. Adler AJ, Filippi V, Thomas SL, et al. Quantifying the global burden of morbidity due to unsafe abortion: magnitude in hospital-based studies and methodological issues. International Journal of Gynecology \& Obstetrics 2012;118(Suppl 2):S65-S77.

11. Bartlett LA, Berg CJ, Shulman HB, et al. Risk factors for legal induced Abortion-Related mortality in the United States. Obstetrics \& Gynecology 2004;103:729-37.

12. Jones EF, Forrest JD. Underreporting of abortion in surveys of U.S. women: 1976 to 1988. Demography 1992;29:113-26.

13. Udry JR, Gaughan M, Schwingl PJ, et al. A medical Record linkage analysis of abortion underreporting. Family Planning Perspectives 1996;28:228-31.

14. Rees H, Katzenellenbogen J, Shabodien R, et al. The epidemiology of incomplete abortion in South Africa. South African Medical Journal 1997:87:432-7.

15. Altijani N, Carson C, Choudhury SS, et al. Stillbirth among women in nine states in India: rate and risk factors in study of 886,505 women from the annual health survey. BMJ Open 2018;8:e022583.

16. Office of Registrar General \& Census Commissioner MoHA Gol. Annual health survey report: a report on core and vital health indicators Part I, 2014.

17. Vyas S, Kumaranayake L. Constructing socio-economic status indices: how to use principal components analysis. Health Policy and Planning 2006;21:459-68.

18. Filmer D, Pritchett LH. Estimating wealth effects without expenditure Data-or tears: an application to educational Enrollments in states of India. Demography 2001;38:115-32.

19. Wagstaff A, Watanabe N. What difference does the choice of Ses make in health inequality measurement? Health Econ. 2003;12:885-90.

20. Pedersen A, Mikkelsen E, Cronin-Fenton D, et al. Missing data and multiple imputation in clinical epidemiological research. Clin Epidemiol 2017:9:157-66.

21. Banerjee SK, Andersen K. Exploring the pathways of unsafe abortion in Madhya Pradesh, India. Global Public Health 2012;7:882-96.

22. Fusco CLB, Silva RdeSe, Andreoni S. Unsafe abortion: social determinants and health inequities in a vulnerable population in São Paulo, Brazil. Cad. Saúde Pública 2012;28:709-19.

23. Arambepola C, Rajapaksa LC. Risk of unsafe abortion associated with long-term contraception behaviour: a case control study from Sri Lanka. BMC Pregnancy Childbirth 2017;17.

24. Biney AAE, Atiglo DY. Examining the association between motivations for induced abortion and method safety among women in Ghana. Women \& Health 2017;57:1044-60.

25. WHO. From concept to measurement: operationalizing WHO's definition of unsafe abortion. Available: http://www.who.int/bulletin/ volumes/92/3/14-136333/en/ [Accessed 5 Feb 2019].

26. DaVanzo J, Rahman M. Pregnancy termination in Matlab, Bangladesh: trends and correlates of use of safer and less-safe methods. IPSRH 2014:40:119-26.

27. lyengar $\mathrm{K}$, lyengar $\mathrm{SD}$. Improving access to safe abortion in a rural primary care setting in India: experience of A service delivery intervention. Reprod Health 2016;13.

28. Elul B, Bracken H, Verma S, et al. Unwanted pregnancy and induced abortion in Rajasthan, India: a qualitative exploration 2004.

29. Ganatra B, Manning V, Pallipamulla SP. Availability of medical abortion pills and the role of chemists: a study from Bihar and Jharkhand, India. Reprod Health Matters 2005;13:65-74. 
30. Zavier AJF, Jejeebhoy S, Kalyanwala S. Factors associated with second trimester abortion in rural Maharashtra and Rajasthan, India. Global Public Health 2012;7:897-908.

31. Marston C, Cleland J. Relationships between contraception and abortion: a review of the evidence. International Family Planning Perspectives 2003;29:6-13.

32. Miller G, Valente C. Population policy: Abortion and modern contraception are substitutes. Demography 2016;53:979-1009.

33. Maina BW, Mutua MM, Sidze EM. Factors associated with repeat induced abortion in Kenya. BMC Public Health 2015;15.

34. WHO. The effects of contraception on obstetric outcomes. Available: http://www.who.int/reproductivehealth/publications/family_planning/ 9241592257/en/ [Accessed 5 Feb 2019].
35. Bankole A, Sedgh G, Oye-Adeniran BA, et al. ABORTION-SEEKING behaviour among Nigerian women. J Biosoc Sci 2008:40:247-68.

36. Hirve SS, law A. Abortion law, policy and services in India: a critical review. Reproductive Health Matters 2004;12:114-21.

37. Robitaille M-C, Chatterjee I. Sex-selective Abortions and Infant Mortality in India: The Role of Parents' Stated Son Preference. The Journal of Development Studies 2018;54:47-56.

38. Unnithan-Kumar M. Female selective abortion - beyond 'culture': family making and gender inequality in a globalising India. Culture, Health \& Sexuality 2010;12:153-66.

39. World Health Organization DoRHaR. Preventing gender-biased sex selection: an Interagency statement OHCHR, UNFPA, UNICEF, un women and who, 2011. 